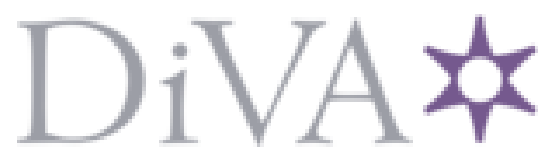

http://www.diva-portal.org

\title{
Postprint
}

This is the accepted version of a paper published in Journal of Anxiety Disorders. This paper has been peer-reviewed but does not include the final publisher proof-corrections or journal pagination.

Citation for the original published paper (version of record):

Arnberg, F., Bergh Johannesson, K., Michel, P. (2013)

Prevalence and Duration of PTSD in Survivors Six Years After a Natural Disaster.

Journal of Anxiety Disorders, 27(3): 347-352

http://dx.doi.org/10.1016/j.janxdis.2013.03.011

Access to the published version may require subscription.

N.B. When citing this work, cite the original published paper.

Permanent link to this version:

http://urn.kb.se/resolve?urn=urn:nbn:se:uu:diva-197606 


\section{Prevalence and Duration of PTSD in Survivors \\ Six Years After a Natural Disaster}

Filip K. Arnberg, ${ }^{a}$ Kerstin Bergh Johannesson, ${ }^{\text {a† }}$ Per-Olof Michel ${ }^{\mathrm{a}}$

${ }^{a}$ National Centre for Disaster Psychiatry, Department of Neuroscience, Uppsala University, Sweden.

Postal address:

National Centre for Disaster Psychiatry, Department of Neuroscience, Akademiska sjukhuset, ing 103 tr,

SE-751 85 Uppsala, Sweden

E-mail: filip.arnberg@neuro.uu.se; kerstin.bergh.johannesson@akademiska.se;

per-olof.michel@neuro.uu.se

${ }^{\dagger}$ Family name: Bergh Johannesson

\section{Corresponding author}

Filip K. Arnberg

Postal Adress: National Centre for Disaster Psychiatry, Department of Neuroscience, Akademiska sjukhuset ing 15 3tr,

SE-751 85 Uppsala, Sweden. Phone: +46-18 61188 98. Fax: +46-18 6118890

E-mail: filip.arnberg@neuro.uu.se

\section{Short title}

PTSD 6 years after a natural disaster 


\begin{abstract}
The present study aimed to examine the prevalence of posttraumatic stress disorder (PTSD) in survivors with low levels of risk factors for PTSD. The sample included 142 adults $(58 \%$ women, $54 \%$ university education, $93 \%$ employed/students/retired) on vacation in Southeast Asia during the 2004 Indian Ocean disaster. Semi-structured clinical interviews (SCID-I) were performed after 6 years including PTSD, depression, specific phobia, and alcohol abuse. The 6-year prevalence of PTSD was $11.3 \%$ and the current prevalence was $4.2 \%$, with onset mainly within 1 month and remission within 3 years post-disaster. Suicidal ideation and comorbidity were common in PTSD cases. Lifetime prevalence of depression was $19 \%$, specific phobia 7\%, and alcohol abuse 4\%. The findings suggest elevated levels of PTSD but not other disorders as compared with general population samples, but still lower levels than other disaster samples. Despite benign circumstances, however, the course and burden of PTSD were comparable to similar studies.
\end{abstract}

Keywords: Disasters; Posttraumatic Stress Disorder; Mental Health; Major Depression; Chronicity (Disorders); Diagnosis 


\section{Introduction}

Disasters challenge world societies to prepare for and respond to the needs of scores of victims worldwide. An efficient societal response is based on proper estimates of the incidence of psychological disorder. Numerous studies have assessed the incidence and prevalence of posttraumatic stress disorder (PTSD; American Psychiatric Association, 2000) after disasters (Neria, Nandi, \& Galea, 2008), which is a disabling disorder related to high rates of comorbidity and suicidal ideation (Cougle, Resnick, \& Kilpatrick, 2009). Yet, despite consistent findings that PTSD is unlikely to remit if persisting beyond 6 years (Green, Lindy, Grace, \& Leonard, 1992; Hull, Alexander, \& Klein, 2002; North, Oliver, \& Pandya, 2012), the overwhelming majority of studies have been conducted within the first 2 years postdisaster (Norris, 2006). Further, extant studies of long-term PTSD concern events that entailed severe secondary and collateral stressors that may exacerbate or prolong the prevalence rates of PTSD (Arnberg, Eriksson, Hultman, \& Lundin, 2011; Brewin, Andrews, \& Valentine, 2000): For example, substantial loss of property or possessions (Green et al., 1992), prolonged anxiety and fear because of terrorist attacks (North, Pfefferbaum, Kawasaki, Lee, \& Spitznagel, 2011), and unemployment (Bøe, Holgersen, \& Holen, 2011; Hull et al. 2002). Severe hardships in the wake of disaster confound estimates of the capacity for a lifethreatening experience to produce chronic PTSD (Kessler et al., 2008). Because such collateral stressors are commonplace and because of a lack of long-term studies, there is uncertainty about the toxicity of the qualifying stressor itself, which is the purported causal agent in PTSD.

PTSD, specific phobia, and depression have been found to increase in prevalence after disasters (Norris et al., 2002). Increased alcohol consumption after disasters has also been noted, although recent findings suggest that the onset of alcohol abuse may often precede the disaster exposure (North, Pfefferbaum, et al., 2011). Prevalence estimates of PTSD after 
natural disasters range from 4 to $60 \%$, with the majority of studies reporting estimates below $30 \%$ (Neria et al., 2008).

A major influence on the estimates of PTSD is the severity of the participants' disaster exposure (Basoglu, Kilic, Salcioglu, \& Livanou, 2004; Bergh Johannesson et al., 2009). Apart from being a key determinant for PTSD, systematic differences in exposure severity have been pointed out as a potential confounder, explaining the higher rates of psychiatric morbidity after anthropogenic (i.e., disasters where the determinants or agents of the destruction were human-caused) versus natural disasters (Neria et al., 2008; North et al., 2012). Often the survivors' level of exposure is not examined thoroughly in epidemiologic surveys despite that the severity of exposure is crucial in understanding the psychological toxicity of traumatic events (North, Pollio, et al., 2011).

Further affecting the link between disaster and outcome, centripetal disasters, which are events that strike an extant community of people, may severely disrupt such life domains as housing, occupation, and leisure activities. The event may deplete social resources in the community and hence obstruct social support, which is an important salutogenic factor after disasters (Arnberg, Hultman, Michel, \& Lundin, 2012; Kaniasty \& Norris, 2009). The nearly ubiquitous presence of secondary or collateral stressors in the aftermath of disasters, especially after centripetal disasters, affects the incidence of PTSD and provides little insight into the potential of the life-threatening event itself to bring about PTSD (Galea et al., 2007; Tracy, Norris, \& Galea, 2011). Studies sometimes report an association between post-disaster stressors and PTSD, generally showing a small to moderate positive association (Brewin et al., 2000). Finally, as noted above, the rather short time to follow-up in most epidemiological studies after disasters suggests that current estimates of the total psychological burden in disaster victims fail to represent the long-standing nature PTSD (Arnberg et al., 2011; Green et al., 1992; Norris, 2006). 
The present study aims to estimate the prevalence and incidence of PTSD 6 years after the 2004 Indian Ocean earthquake and the resulting tsunamis in a sample of afflicted Swedish tourists who were repatriated shortly after the event. This study is part of a national longitudinal follow-up of Swedish survivors that until now has relied on mail surveys (Bergh Johannesson et al., 2009). Participants' self-report data from surveys of the larger sample were included to characterize cases of PTSD and provide prospective data on associated suicidal ideation. Because of the characteristics of the sample and the event, the study could shed light on the prevalence of PTSD because of the disaster experience itself. In particular, the sample included tourists with high rates of employment and high educational attainment, as well as low levels of pre-disaster morbidity and post-disaster stressors, who were repatriated to unscathed homes after the event.

\section{Materials and Methods}

\subsection{Procedure and participants}

The Swedish authorities registered all Swedish citizens who were repatriated from destinations in Southeast Asia during the first 3 weeks after the disaster. The 21 Swedish county councils were asked for approval of the inclusion of county inhabitants in the followup and 10 agreed $(n=10,116)$. The interviews were conducted 74 months after the disaster with a subsample of the national cohort. The assessments in the national cohort include a mail survey 14 months after the disaster (T1, $n=4,932$; Bergh Johannesson et al., 2009) and two following surveys of the respondents from the first survey: at 37 months (T2, $n=3,457$; Bergh Johannesson, Lundin, Fröjd, Hultman, \& Michel, 2011) and one month after the interviews (i.e., 75 months after the disaster; T3, $n=2,643$; Bergh Johannesson, Arnberg, \& Michel, 2012). A random sample of 200 individuals was selected from respondents at T2 who had provided consent to participate in a telephone interview $(n=2,104,61 \%)$ and had 
indicated in the survey at $\mathrm{T} 1$ that they were directly exposed to the disaster as described below.

Disaster exposure was established with 30 multiple-choice items included in the survey at T1 about the participants' experiences during and shortly after the event. A set of exposure criteria was selected from the 30 items based on previous analyses of the present sample (Bergh Johannesson et al., 2009). Participants were eligible for inclusion in the present study if they had been caught in or chased by the tsunami or experienced one or more of the following: bereavement of family/relatives, physical injuries to themselves or others, and witnessing distressing consequences of the disaster (dead bodies, others suffering, or forlorn children). In all, 1,684 individuals fulfilled the exposure criteria and agreed to an interview. The participants who consented to the interview were similar in age, gender, and employment status to those who declined (lowest $p=.27$ ). However, participants who declined to participate reported somewhat higher levels of posttraumatic stress according to the Impact of Event Scale_-Revised (IES-R; Weiss, 2004) at T2 $\left(M_{\text {diff }}=3.65\right)$, $t(3359)=7.22, p<.001$. Of the 200 participants approached for interviews, 27 declined and 31 could not be reached. Completing the interviews was associated with older age $\left(M_{\text {diff }}=6.2\right.$ years), $t(198)=2.89, p=.004$, but not with other demographic variables or posttraumatic stress (lowest $p=.42$ ). The study was approved by the Ethical Review Board in Uppsala, Sweden

\subsection{Measures}

The Structured Clinical Interview for DSM-IV Axis I Disorders (SCID-I) was used to assess current and lifetime PTSD (First, Spitzer, Gibbon, \& Williams, 1997/1998). The interview also included the modules for depression, social phobia, specific phobia, alcohol, and substance abuse. The interviewers were 10 candidate level students from the master's program in psychology (at least 3 years of full-time studies). Before the interviews, the 
interviewers received 8 hours of formal training by the present authors. The principal author, who was blind to the results of the interviews, audited a random selection of the interviews $(n=20)$. A Cohen's kappa of 1.0 indicated excellent inter-rater reliability. The participants' treatment history was also systematically assessed during the interview: The interviewers asked about the type, duration, and frequency of any treatment that the participants received and whether the treatment was related to the disaster.

The data collected from surveys included suicidal ideation, history of stressful life events before the tsunami, and an assessment of personality. Suicidal ideation was retrieved from the surveys at T1-T3 as assessed by a single item that asked the participants whether they had had thoughts about suicide in the past 12 months (yes/no/unable to recall). The participants' history of stressful life events before the disaster was assessed in the survey at T1 by a Swedish life event checklist (Bergsten Brucefors, Sidén Silfver, \& Schulman, 2001) with 15 dichotomous items (yes/no responses) covering a range of stressful life events (e.g., accident, disaster, war/terror, violence/abuse, serious illness/injury, serious conflict with significant others, death of significant others, unemployment, and severe economic hardships). All 15 events are among the top 20 most distressing events on the Revised Social Adjustment Rating Scale (Hobson et al., 1998). Stressful events post-disaster were examined during the interview by using the above life event checklist appended with an "other event" option.

The Big Five Inventory (BFI; John, Donahue, \& Kentle, 1991) was administered in the survey at T3. The BFI is a brief personality inventory comprised of 44 items that are rated on a five-point Likert scale. The items form five subscales of the big five personality dimensions: agreeableness, conscientiousness, extraversion, neuroticism, and openness (John, Robins, \& Pervin, 2008). The BFI has good psychometric properties, with Cronbach's alpha 
for the subscales ranging from 0.76 to 0.82 in the present sample and a 3-month test-retest reliability from 0.80 to 0.90 (John et al., 2008).

\subsection{Statistical analysis}

A power analysis indicated that with a total population of 6-8,000 Swedish tourists in Southeast Asia (as estimated by tourist agencies) and an estimated incidence of $20 \%$ for PTSD, a sample of 200 individuals would provide a 95\% confidence interval (CI) of approximately 10 percentage points. For group comparisons, independent $t$-tests, supplemented by a standardized mean difference (the Cohen's $d$ effect size; Cohen, 1988), were used for continuous variables and $\chi^{2}$ tests for nominal variables. No formal tests were carried out for comparison of PTSD cases and non-cases on categorical variables because of insufficient power. A likelihood ratio $(95 \% \mathrm{CI})$ was calculated for the prevalence estimates of current and lifetime disorders. All analyses were two-tailed and the level of significance was set at $p<.05$. The analyses were performed with SPSS v. 20 for Mac (IBM, Chicago, IL).

\section{Results}

Telephone interviews were completed for 142 (71\%) of the 200 randomly selected participants. The sample included 82 women (58\%) and had an average age of 49.7 years $(S D=13.1)$. The majority were married or cohabiting $(n=113,80 \%)$, had a university education ( $n=77,54 \%$ ), and were either employed, students, or had retired from full-time employment $(n=132,93 \%)$. One participant reported a history of any psychological treatment or pharmacotherapy before the disaster. As indicated in the T1 survey, the median number of stressful life events before the disaster was two (IQR $=2$, range $0-11)$. As indicated in the T1 survey, $97 \%$ of the participants had been visiting coastal areas by the Andaman Sea (e.g., Phuket, Khao Lak, and Krabi) while 3\% indicated "other areas". More than half of the participants $(n=92,65 \%)$ had been caught in or chased by the tsunami waves 
that inundated coastal areas. Nineteen participants $(13 \%)$ had been bereaved of a significant other in the disaster.

\subsection{Prevalence}

A majority of the participants fulfilled the PTSD A1 criterion (exposure to a lifethreatening event; $n=103,73 \%$ ) and the A2 criterion (intense fear, helplessness, horror; $n=87,61 \%)$. Sixteen participants fulfilled the criteria for a lifetime diagnosis of PTSD $(11.3 \%, 95 \%$ CI $[6.8,17.1])$, whereof six participants fulfilled the criteria for a current diagnosis of PTSD $(4.2 \%, 95 \%$ CI $[1.7,8.6])$. All cases of PTSD were related to the disaster and no cases were found before the disaster. Thus, the lifetime prevalence estimate of PTSD was indicative of a 6-year post-disaster incidence of PTSD. The prevalence of the four disorders targeted in the interview is listed in Table 1. Specific phobias included travel phobia $(n=4)$, claustrophobia, spider phobia, snake phobia, blood phobia, and one case of water/sea phobia with onset before the disaster but had worsened after the trauma.

\subsection{Characteristics of PTSD cases}

A majority of the PTSD cases were women (see Table 2 for further characteristics). Notably, $40-50 \%$ of the participants with a lifetime PTSD diagnosis reported suicidal ideation across surveys. PTSD was associated with comorbidity in 14 of 16 participants (88\%), whereas only $2 / 126(1.6 \%)$ in the non-PTSD group fulfilled criteria for more than one

of the disorders assessed herein. Time to onset of PTSD symptoms was within 1 month for 13 cases, after approximately 6 months for two cases, and after 18 months for one case $(M=2$ months, $S D=1.17)$. The duration of PTSD ranged from 6 months to 3 years in the 10 remitted cases, whereas the duration for the 6 cases with ongoing PTSD ranged from 4.5 to 6 years (Figure 1). There were 115 participants who had valid BFI scores in the T3 survey. Independent $t$-tests of the Big Five dimensions indicated differences only in that PTSD was 
associated with higher levels of neuroticism $(M=3.0, S D=0.45)$ than in non-cases of PTSD $(M=2.3, S D=0.78), t(113)=3.06, p=.003, d=0.88$.

\subsection{Stressful life events and treatment}

The majority of the participants $(n=77,54 \%)$ reported no other stressful life events after the disaster, whereas $42(30 \%)$ had experienced one event and $23(16 \%)$ had experienced two to four events $(M=0.71, S D=0.96)$. PTSD was related to a higher frequency of pre-disaster stressful life events $\left(M_{\text {diff }}=0.47, S E_{\text {diff }}=0.25\right), t(140)=2.46, p=$ $.015, d=0.66$, but was not related to post-disaster stressful life events $\left(M_{\text {diff }}=0.47, S E_{\text {diff }}=\right.$ $0.53), t(140)=1.84, p=.18$. Conversely, depression was not related to pre-disaster stressful events $\left(M_{\text {diff }}=0.55, S E_{\text {diff }}=0.43\right), t(140)=1.28, p=.20$, but was related to a higher frequency of post-disaster stressful events $\left(M_{\text {diff }}=0.54, S E_{\text {diff }}=0.20, t(140)=2.67, p=.008\right.$, $d=0.58 .{ }^{1}$ Given the unexpected finding that post-disaster stressors were not associated with PTSD, we tested the association in only non-bereaved participants. In this subsample PTSD was related to a higher frequency of stressful events after the disaster $\left(M_{\mathrm{diff}}=0.90, S E_{\mathrm{diff}}=\right.$ $0.32), t(120)=2.77, p=.006, d=0.91$.

For psychological concerns related to the disaster, 52 participants $(37 \%)$ reported having received treatment, whereof $5(3.5 \%)$ were currently in treatment. Most participants who were given treatment received some form of talk therapy only (i.e. seeing a mental health professional, counselor, or clergy; $n=43,81 \%$ ), whereas eight participants received both talk therapy and pharmacotherapy, and one received pharmacotherapy. Fifteen of 16 (94\%) participants who developed PTSD after the event and 37 (29\%) of the participants without PTSD received treatment for psychological concerns related to the disaster. Eight participants received treatment for physical injuries caused by the event.

\footnotetext{
${ }^{1}$ Similar results were obtained in an ANOVA performed with PTSD and depression entered simultaneously. For events after the disaster, there was a small relation between depression and number of stressors, $F(1,139)=$ $3.83, p=.05, \eta_{\mathrm{p}}{ }^{2}=0.027$, but no relation was found between PTSD and stressors, $F(1,139)=0.18, p=.67, \eta_{\mathrm{p}}{ }^{2}$ $=.001$.
} 


\section{Discussion}

The present study investigated PTSD in Swedish survivors 6 years after the 2004 Indian Ocean disaster. The 6-year incidence of PTSD was $11.3 \%$ and the point prevalence of PTSD was $4.2 \%$. The lifetime prevalence of any of the four disorders (PTSD, MDE, specific phobias, and alcohol abuse) targeted in this study was 25\%. Moreover, PTSD after the event was related to high rates of suicidal ideation across assessments from 14 months to 6 years.

The 6-year incidence of PTSD in this sample was somewhat higher than the conditional probability of probable PTSD given at least one trauma as assessed by self-report scales in a nationally representative sample in Sweden (6.9\%; Frans, Rimmö, Åberg, \& Fredrikson, 2005) In contrast, the prevalence of both current and lifetime depression was highly similar to comparable surveys of the Norwegian general population (Kringlen, Torgersen, \& Cramer, 2001; Sandanger, Nygard, Ingebrigtsen, Sorensen, \& Dalgard, 1999) and the prevalence of specific phobias was similar to findings from studies of the general population in Norway, the USA, and the Netherlands (Bijl, Ravelli, \& van Zessen, 1998; Kessler, Chiu, Demler, Merikangas, \& Walters, 2005; Kringlen et al., 2001). The high educational level and a high rate of employment in the present sample, however, warrant caution in comparisons with population-based studies.

A Norwegian follow-up of tsunami survivors with sample characteristics being very similar to that of the present study found that one third of the Norwegian participants developed PTSD within 2.5 years after the event (Hussain, Weisaeth, \& Heir, 2011). However, all participants in their study fulfilled the PTSD A1 criterion and one quarter were bereaved of a family member, which can be compared with one quarter fulfilling the A1 criterion and $13 \%$ bereaved in the present sample. Indeed, more than one third of the PTSD cases were bereaved of significant others; the 6-year prevalence in bereaved participants was $6 / 19(32 \%)$. In comparison, for the non-bereaved participants, there were 10/113 (8.8\%) who 
developed PTSD, which underscores bereavement as a risk factor for long-term PTSD (Arnberg et al., 2011). Further, our prevalence rates were lower than in studies of directly exposed victims from both natural and anthropogenic disasters (Bøe et al., 2011; Favaro, Zaetta, Colombo, \& Santonastaso, 2004; Hull et al., 2002; North, Pfefferbaum, et al., 2011; North, Pollio, et al., 2011). This study concerned an event very remote to the homes of the survivors and that the beliefs common in people with PTSD about the world as dangerous (e.g., no place is safe) may have been easier to reevaluate by the survivors in their processing of the event, as compared to the more plausible (and realistic) negative beliefs about the world if the index trauma took place in or close to the survivors' homes. One may assume that, in addition to the lack of secondary stressors, the remoteness of the event contributed to the low prevalence. Without direct contrasts, however, the comparisons of prevalence rates remain tentative.

Regarding the course of PTSD, no more cases were remitted after 36 months and current PTSD was found in a little more than one third of those who developed PTSD after the disaster. Nearly all participants with PTSD indicated that they received some form of treatment. These findings are highly comparable with what was found in the National Comorbidity Survey (NCS), in which the median time to remission from PTSD was 36 months for participants who received treatment (Kessler, Sonnega, Bromet, Hughes, \& Nelson, 1995). The NCS study also found that PTSD failed to remit in somewhat more than one third of persons even after many years despite treatment (beyond 6 years further recovery was nearly nonexistent). Despite discrepant base rates in the population under study, the course of PTSD in the longer term may operate similarly across studies. The present findings concur with established findings on risk factors for PTSD, such as female gender, neuroticism, more severe disaster exposure, and traumatic bereavement (Neria et al., 2008; North, Pollio, et al., 2011). In contrast to the low prevalence and incidence of PTSD, those 
who developed PTSD were heavily burdened by chronic symptoms, comorbidity, and a high prevalence of suicidal ideation over the 6 years of follow-up.

There are limitations to the present study that must be recognized. First, naturalistic studies cannot be expected to find a zero frequency of post-disaster stressors. A number of survivors, and particularly many in the PTSD group, suffered traumatic bereavement. Even though traumatic bereavement can be seen as a peritraumatic event (Bergh Johannesson et al., 2009), it is reasonable that bereavement is associated with significant long-term post-disaster stress. For example, bereavement seemed to have overshadowed the association between post-disaster stressors and PTSD, although these findings are only tentative. The absence of stressful events needs to be considered also in light of the fact that many participants received treatment related to the disaster.

Second, there could have been a slight attrition bias both at T1 and T2 as well as in the selection process for the interviews. Non-response to large community surveys after the 2004 disaster seems to be more prevalent among less exposed individuals (Hussain, Weisæth, \& Heir, 2009). Conversely, the participants who responded to the mail surveys but declined participation in the interview had somewhat higher levels of posttraumatic stress. The small number of PTSD cases yielded wide confidence intervals and precluded formal assessment of categorical correlates of PTSD. The intended sample size of 200 was estimated based on a higher rate of PTSD and higher participation rate. Of note is that the current sample size is comparable to similar studies (Norris, 2006). The analysis of a relation between PTSD and personality facets included somewhat fewer participants because of attrition at $\mathrm{T} 3$, and is further limited because the participants' mental states could have influenced their responses to the personality measure.

As a final limitation, the use of telephone interviews may have compromised the validity or reliability of the diagnoses. However, phone interviews seem to be a reliable 
method to assess PTSD (Aziz \& Kenford, 2004). Moreover, the inter-rater reliability was excellent. Nonetheless, lifetime prevalence was assessed retrospectively, which may have attenuated the rates of PTSD and other disorders (Moffitt et al., 2010). Finally, several other disorders were not assessed, which was done with the intention to lessen the burden on the participants and improve the quality of responses. Our findings should therefore not be construed as a full account of psychiatric morbidity after the disaster in that it remains a possibility that other disorders present in the sample influenced the prevalence and course of PTSD.

\subsection{Conclusion}

The limitations notwithstanding, the present study taps into the psychological toxicity of experiencing a disastrous event. Exposure to a natural disaster that was very remote from the survivors' homes and followed by few secondary stressors was associated with a low incidence of long-term PTSD in a sample of mostly employed and highly educated survivors. The rates of depression, specific phobia, and alcohol abuse were not markedly higher than corresponding rates from general population samples. Nonetheless, the course of PTSD was similar to other studies evaluating PTSD in persons affected by natural disaster. Moreover, the burden of PTSD seemed as heavy as reported in other studies in that PTSD was associated with comorbidity, suicidal ideation, and a prolonged course. The duration of PTSD was 2 years or more for half of the cases, underscoring the risk of chronic ill-health for survivors who develop PTSD after a disaster despite fairly advantageous circumstances. 


\section{Acknowledgements}

This work was supported by the Swedish National Board of Health and Welfare and part of a national follow-up done in cooperation with the Center for Family and Community Medicine and the Department of Epidemiology and Biostatistics, Karolinska Institutet, Stockholm, Sweden. The funding source had no involvement in study design or collection, analysis, and interpretation of data. 


\section{References}

American Psychiatric Association. (2000). Diagnostic and statistical manual of mental disorders (4th ed., text rev.). Washington, DC: Author.

Arnberg, F. K., Eriksson, N.-G., Hultman, C. M., \& Lundin, T. (2011). Traumatic bereavement, acute dissociation, and posttraumatic stress: 14 years after the MS Estonia disaster. Journal of Traumatic Stress, 24(2), 183-190. doi:10.1002/jts.20629

Arnberg, F. K., Hultman, C. M., Michel, P.-O., \& Lundin, T. (2012). Social support moderates posttraumatic stress and general distress after disaster. Journal of Traumatic Stress, 25(6), 721-727. doi:10.1002/jts.21758

Aziz, M. A., \& Kenford, S. (2004). Comparability of telephone and face-to-face interviews in assessing patients with posttraumatic stress disorder. Journal of Psychiatric Practice, 10(5), 307-313.

Basoglu, M., Kilic, C., Salcioglu, E., \& Livanou, M. (2004). Prevalence of posttraumatic stress disorder and comorbid depression in earthquake survivors in Turkey: An epidemiological study. Journal of Traumatic Stress, 17(2), 133-141. doi:10.1023/B:JOTS.0000022619.31615.e8

Bergh Johannesson, K., Arnberg, F. K., \& Michel, P.-O. (2012). Svenskarna som överlevde tsunamin mår relativt bra: Uppföljning sex år efter katastrofen 2004. [Swedish survivors from the tsunami are recovering: A follow-up six years after the disaster in 2004]. Lakartidningen, 109(37), 1607-1609.

Bergh Johannesson, K., Lundin, T., Fröjd, T., Hultman, C. M., \& Michel, P.-O. (2011). Tsunami-exposed tourist survivors: Signs of recovery in a 3-year perspective. Journal of Nervous and Mental Disease, 199(3), 162-169.

doi:10.1097/NMD.0b013e31820c73d1 
Bergh Johannesson, K., Michel, P.-O., Hultman, C. M., Lindam, A., Arnberg, F., \& Lundin, T. (2009). Impact of exposure to trauma on posttraumatic stress disorder symptomatology in Swedish tourist tsunami survivors. Journal of Nervous and Mental Disease, 197(5), 316-323. doi:10.1097/NMD.0b013e3181a206f7

Bergsten Brucefors, A., Sidén Silfver, Y., \& Schulman, A. (2001). Psykologiska och sociala effekter av trafikolycka med lindriga eller inga personskador [Psychological and social effects of traffic accidents with mild or no injury] (2001:3). Stockholm, Sweden: Stockholm County Council.

Bijl, R. V., Ravelli, A., \& van Zessen, G. (1998). Prevalence of psychiatric disorder in the general population: Results of The Netherlands Mental Health Survey and Incidence Study (NEMESIS). Social Psychiatry and Psychiatric Epidemiology, 33(12), 587595. doi:10.1007/s001270050098

Brewin, C. R., Andrews, B., \& Valentine, J. D. (2000). Meta-analysis of risk factors for posttraumatic stress disorder in trauma-exposed adults. Journal of Consulting and Clinical Psychology, 68(5), 748-766. doi:10.1037/0022-006X.68.5.748

Bøe, H. J., Holgersen, K. H., \& Holen, A. (2011). Mental health outcomes and predictors of chronic disorders after the North Sea oil rig disaster: 27-year longitudinal follow-up study. Journal of Nervous and Mental Disease, 199(1), 49-54.

doi:10.1097/NMD.0b013e31820446a8

Cohen, J. (1988). Statistical power analysis for the behavioral sciences (2nd ed.). Hillsdale, NJ: Erlbaum.

Cougle, J. R., Resnick, H., \& Kilpatrick, D. G. (2009). PTSD, depression, and their comorbidity in relation to suicidality: Cross-sectional and prospective analyses of a national probability sample of women. Depression and Anxiety, 26(12), 1151-1157. doi:10.1002/da.20621 
Favaro, A., Zaetta, C., Colombo, G., \& Santonastaso, P. (2004). Surviving the Vajont disaster: Psychiatric consequences 36 years later. Journal of Nervous and Mental Disease, 192(3), 227-231. doi:10.1097/2F01.nmd.0000117590.81374.7c

First, M. B., Spitzer, R. L., Gibbon, M., \& Williams, J. B. W. (1998). Structured Clinical Interview for DSM-IV Axis I disorders (SCID I). (J. Herlofson, Trans.). Stockholm, Sweden: Pilgrim Press. (Original work published 1997).

Frans, Ö., Rimmö, P. A., Åberg, L., \& Fredrikson, M. (2005). Trauma exposure and posttraumatic stress disorder in the general population. Acta Psychiatrica Scandinavica, 111(4), 291-299. doi:10.1111/j.1600-0447.2004.00463.x

Galea, S., Brewin, C. R., Gruber, M., Jones, R. T., King, D. W., King, L. A., . . Kessler, R. C. (2007). Exposure to hurricane-related stressors and mental illness after Hurricane Katrina. Archives of General Psychiatry, 64(12), 1427-1434. doi:10.1001/archpsyc.64.12.1427

Green, B. L., Lindy, J. D., Grace, M. C., \& Leonard, A. C. (1992). Chronic posttraumatic stress disorder and diagnostic comorbidity in a disaster sample. Journal of Nervous \& Mental Disease, 180(12), 760-766. doi:10.1097/00005053-199212000-00004

Hobson, C. J., Kamen, J., Szostek, J., Nethercut, C. M., Tiedmann, J. W., \& Wojnarowicz, S. (1998). Stressful life events: A revision and update of the social readjustment rating scale. International Journal of Stress Management, 5(1), 1-23. doi:10.1023/A:1022978019315

Hull, A. M., Alexander, D. A., \& Klein, S. (2002). Survivors of the Piper Alpha oil platform disaster: Long-term follow-up study. British Journal of Psychiatry, 181(5), 433-438. doi:10.1192/bjp.181.5.433 
Hussain, A., Weisaeth, L., \& Heir, T. (2011). Psychiatric disorders and functional impairment among disaster victims after exposure to a natural disaster: A population based study. Journal of Affective Disorders, 128(1-2), 135-141. doi:10.1016/j.jad.2010.06.018

Hussain, A., Weisæth, L., \& Heir, T. (2009). Nonresponse to a population-based postdisaster postal questionnaire study. Journal of Traumatic Stress, 22(4), 324-328. doi:10.1002/jts.20431

John, O. P., Donahue, E. M., \& Kentle, R. L. (1991). The Big Five Inventory-Versions $4 a$ and 54. Berkeley, CA: University of California, Berkeley, Institute of Personality and Social Research.

John, O. P., Robins, R. W., \& Pervin, L. A. (Eds.). (2008). Handbook of personality: Theory and research (3rd ed.). New York, NY: Guilford Press.

Kaniasty, K., \& Norris, F. H. (2009). Distinctions that matter: Received social support, perceived social support, and social embeddedness after disasters. In Y. Neria, S. Galea \& F. H. Norris (Eds.), Mental health and disasters (pp. 175-202). New York, NY: Cambridge University Press.

Kessler, R. C., Chiu, W. T., Demler, O., Merikangas, K. R., \& Walters, E. E. (2005). Prevalence, severity, and comorbidity of 12-month DSM-IV disorders in the National Comorbidity Survey Replication. Archives of General Psychiatry, 62(6), 617-627. doi:10.1001/archpsyc.62.6.617

Kessler, R. C., Galea, S., Gruber, M. J., Sampson, N. A., Ursano, R. J., \& Wessely, S. (2008). Trends in mental illness and suicidality after Hurricane Katrina. Molecular Psychiatry, 13(4), 374-384. doi:10.1038/sj.mp.4002119

Kessler, R. C., Sonnega, A., Bromet, E., Hughes, M., \& Nelson, C. B. (1995). Posttraumatic stress disorder in the National Comorbidity Survey. Archives of General Psychiatry, 52(12), 1048-1060. doi:10.1001/archpsyc.1995.03950240066012 
Kringlen, E., Torgersen, S., \& Cramer, V. (2001). A Norwegian psychiatric epidemiological study. American Journal of Psychiatry, 158, 1091-1098. doi:10.1176/appi.ajp.158.7.1091

Moffitt, T. E., Caspi, A., Taylor, A., Kokaua, J., Milne, B. J., Polanczyk, G., \& Poulton, R. (2010). How common are common mental disorders? Evidence that lifetime prevalence rates are doubled by prospective versus retrospective ascertainment. Psychological Medicine, 40(06), 899-909. doi:doi:10.1017/S0033291709991036

Neria, Y., Nandi, A., \& Galea, S. (2008). Post-traumatic stress disorder following disasters: A systematic review. Psychological Medicine, 38(04), 467-480. doi:10.1017/S0033291707001353

Norris, F. H. (2006). Disaster research methods: Past progress and future directions. Journal of Traumatic Stress, 19(2), 173-184. doi:10.1002/jts.20109

Norris, F. H., Friedman, M. J., Watson, P. J., Byrne, C. M., Diaz, E., \& Kaniasty, K. (2002). 60,000 disaster victims speak: Part I. An empirical review of the empirical literature, 1981-2001. Psychiatry: Interpersonal and Biological Processes, 65(3), 207-239. doi:10.1521/psyc.65.3.207.20173

North, C. S., Oliver, J., \& Pandya, A. (2012). Examining a comprehensive model of disasterrelated posttraumatic stress disorder in systematically studied survivors of 10 disasters. American Journal of Public Health, 102(10), e40-e48. doi:10.2105/ajph.2012.300689

North, C. S., Pfefferbaum, B., Kawasaki, A., Lee, S., \& Spitznagel, E. L. (2011). Psychosocial adjustment of directly exposed survivors 7 years after the Oklahoma City bombing. Comprehensive Psychiatry, 52(1), 1-8. doi:10.1016/j.comppsych.2010.04.003 
North, C. S., Pollio, D. E., Smith, R. P., King, R. V., Pandya, A., Suris, A. M., . . .

Pfefferbaum, B. (2011). Trauma exposure and posttraumatic stress disorder among employees of New York City companies affected by the September 11, 2001 attacks on the World Trade Center. Disaster medicine and public health preparedness, 5(Supplement_2), S205-213. doi:10.1001/dmp.2011.50

Sandanger, I., Nygard, J. F., Ingebrigtsen, G., Sorensen, T., \& Dalgard, O. S. (1999).

Prevalence, incidence and age at onset of psychiatric disorders in Norway. Social Psychiatry and Psychiatric Epidemiology, 34(11), 570-579.

doi:10.1007/s001270050177

Tracy, M., Norris, F. H., \& Galea, S. (2011). Differences in the determinants of posttraumatic stress disorder and depression after a mass traumatic event. Depression and Anxiety, 28(8), 666-675. doi:10.1002/da.20838

Weiss, D. S. (2004). The Impact of Event Scale-Revised. In J. P. Wilson \& T. M. Keane (Eds.), Assessing psychological trauma and PTSD (2nd ed., pp. 168-189). New York, NY: Guilford Press. 


\section{Tables}

Table 1

Prevalence of Four Disorders in 142 Survivors 6 Years after the 2004 Indian Ocean Disaster

\begin{tabular}{lccccc}
\hline & \multicolumn{2}{c}{ Lifetime prevalence } & & \multicolumn{3}{c}{ Current prevalence } \\
\cline { 2 - 3 } \cline { 5 - 6 } Disorder & $n$ & $\%[95 \% \mathrm{CI}]$ & & $n$ & $\%[95 \% \mathrm{CI}]$ \\
\hline PTSD $^{\mathrm{a}}$ & 16 & $11.3[6.8,17.1]$ & & 6 & $4.2[1.7,8.6]$ \\
MDE & 27 & $19.0[13.1,26.0]$ & & 4 & $2.8[0.9,6.4]$ \\
Specific phobia & 10 & $7.0[3.6,12.0]$ & & 10 & $7.0[3.6,12.0]$ \\
Alcohol abuse & 6 & $4.2[1.7,8.4]$ & & 1 & $0.7[0.0,3.1]$ \\
Total $^{\mathrm{b}}$ & 36 & $25.4[18.7,32.9]$ & & 15 & $10.6[6.2,16.3]$ \\
\hline
\end{tabular}

Note. $\mathrm{PTSD}=$ posttraumatic stress disorder, $\mathrm{MDE}=$ major depressive episode.

${ }^{\mathrm{a}}$ All PTSD cases were related to the disaster. ${ }^{\mathrm{b}}$ The total $n$ does not reflect the sum of the disorders because of comorbidity. 
Table 2

Characteristics of Participants Who Developed Posttraumatic Stress Disorder (PTSD) within 6 Years after the 2004 Indian Ocean Disaster

\begin{tabular}{|c|c|c|c|c|}
\hline \multirow[b]{2}{*}{ Characteristic } & \multicolumn{2}{|c|}{$\begin{array}{c}\text { PTSD } \\
(n=16)\end{array}$} & \multicolumn{2}{|c|}{$\begin{array}{l}\text { No PTSD } \\
(n=126)\end{array}$} \\
\hline & $n$ & $\%$ & $n$ & $\%$ \\
\hline Women & 12 & 75.0 & 70 & 55.6 \\
\hline Married/partner & 9 & 56.2 & 94 & 74.6 \\
\hline University education & 6 & 37.5 & 71 & 56.3 \\
\hline Caught in waves & 13 & 81.2 & 79 & 62.7 \\
\hline Subjective life threat & 9 & 56.2 & 49 & 40.8 \\
\hline Injured in disaster & 10 & 62.5 & 27 & 21.4 \\
\hline Traumatic bereavement $^{\mathrm{a}}$ & 6 & 37.5 & 13 & 10.3 \\
\hline \multicolumn{5}{|l|}{ Suicidal ideation $^{\mathrm{b}}$} \\
\hline $1^{\text {st }}$ year after event & 8 & 50.0 & 9 & 7.2 \\
\hline $3^{\text {rd }}$ year after event & 7 & 43.8 & 4 & 3.2 \\
\hline $6^{\text {th }}$ year after event & 7 & 43.7 & 5 & 4.0 \\
\hline Disaster-related treatment ${ }^{\mathrm{c}}$ & 15 & 93.8 & 38 & 30.2 \\
\hline \multicolumn{5}{|l|}{ Comorbidity } \\
\hline Major depressive episode & 13 & 81.2 & 14 & 11.1 \\
\hline Specific phobia & 4 & 25.0 & 6 & 4.8 \\
\hline Alcohol abuse & 3 & 18.8 & 3 & 2.4 \\
\hline None of the above & 2 & 12.5 & 106 & 84.1 \\
\hline
\end{tabular}

Note. Exposure variables and suicidal ideation collected from a survey 14 months after the event. All PTSD cases were related to the disaster.

${ }^{a}$ Loss of family, relatives, or friends in the disaster. ${ }^{b}$ Thoughts of suicide in the past 12 months. ${ }^{\mathrm{c}}$ Talk therapy, pharmacotherapy. 


\section{Figure captions}

\section{Figure 1}

Survival curve based on duration of PTSD for 16 participants who developed PTSD within 6 years from the 2004 Indian Ocean disaster. Censored values indicate current PTSD $(n=6)$. In one case onset of PTSD was 18 months after the disaster.



